\title{
Photodegradation of etridiazole by UV radiation during drinking water treatment
}

\author{
Chao Liu, Zhimin Qiang*, Fang Tian, Tao Zhang \\ State Key Laboratory of Environmental Aquatic Chemistry, Research Center for Eco-Environmental Sciences (RCEES), Chinese Academy of Sciences, Beijing 100085, China
}

\section{A R T I C L E I N F O}

\section{Article history:}

Received 31 October 2008

Received in revised form 22 April 2009

Accepted 23 April 2009

Available online 23 May 2009

\section{Keywords:}

Etridiazole fungicide

UV radiation

Photodegradation

Quantum yield

Byproducts

\begin{abstract}
A B S T R A C T
The photodegradation of etridiazole (ETZ) in water by UV radiation at $254 \mathrm{~nm}$ was investigated. Results indicate that the simulated first-order rate constants decreased with the increase of initial ETZ concentration (i.e., 5, 20 and $30 \mu \mathrm{M}$ ), and did not show any pH dependence within the range from 6.0 to 8.0. The quantum yield was $0.46 \pm 0.02 \mathrm{~mol} \mathrm{E}^{-1}$ at $\mathrm{pH} 7.0 . \mathrm{H}_{2} \mathrm{O}_{2}$ was generated at trace levels in the range from 0 to $1.0 \mu \mathrm{M}$ during photodegradation of ETZ. Direct photodegradation was responsible for the decomposition of ETZ in distilled water by UV radiation. Three organic byproducts were identified: 5-ethoxy-3-dichloromethyl-1,2,4-thiadiazole, 5-ethoxy-1,2,4-thiadiazole-3-carboxylic acid and 5-ethoxy-3hydroxyl-1,2,4-thiadiazole. About $90 \%$ of chloro mass in the initial ETZ was released as $\mathrm{Cl}^{-}$at the end of photodegradation. In contrast, the formation of sulfate and nitrate was insignificant. In general, ETZ decayed more quickly in groundwater than in sand-filtered or surface water. It is reasonably deduced that ETZ may not get removed effectively under a typical UV dose of $40 \mathrm{~mJ} \mathrm{~cm}{ }^{-2}$ at most water treatment plants that employ UV radiation for disinfection.
\end{abstract}

(c) 2009 Elsevier Ltd. All rights reserved.

\section{Introduction}

Pesticides are widely used in different forms such as insecticides, herbicides and fungicides as to increase agricultural productivity. However, the wide use of these chemicals may pollute water resources and thus raise human health concern due to their known human toxicity (Dalvi and Howell, 1977). Etridiazole (ETZ, 5-ethoxy-3-trichloromethyl-1,2,4-thiadiazole) is one of the most extensively used fungicides for controlling phycomycetous fungi in plants, tomatoes, turf, and cotton as described by US Environmental Protection Agency (US EPA, 2000). Literature data about its distribution in aqueous environment are very scarce, but the reported maximum concentration of $0.23 \mathrm{ng} \mathrm{m}^{-3}$ of ETZ in Iowa air and its wide usage may predict its occurrence in natural waters (Peck and Hornbuckle, 2005). Based on the generic estimated exposure concentration model, the chronic and acute ETZ concentrations resulting from turf use in related water resources were 32.3 and $230 \mu \mathrm{g} \mathrm{L}^{-1}$, respectively (US EPA, 2000).

ETZ is a toxic chemical that can inhibit the hepatic drug metabolizing enzyme system (Dalvi and Howell, 1977). Potential exposure to ETZ from drinking water may engender the chronic dietary risk as it has been classified as a B2 carcinogen (US EPA, 2000). To avoid the potential threat of ETZ to human beings, drinking water standards have regulated a maximum contaminant level $(\mathrm{MCL})$ in treated waters. For example, Australian drinking water guidelines set an MCL for ETZ at $0.1 \mathrm{mg} \mathrm{L}^{-1}$ (National Health and Medical Research Council of Australia, 2004). The European Union

\footnotetext{
* Corresponding author. Tel.: +86 10 62849632; fax: +86 1062923541 .

E-mail address: qiangz@rcees.ac.cn (Z. Qiang).
}

(EU) drinking water standards more strictly regulate a level for any particular pesticide at $0.0001 \mathrm{mg} \mathrm{L}^{-1}$ and the sum of all pesticides at $0.0005 \mathrm{mg} \mathrm{L}^{-1}$ (EU, 2007).

Once ETZ occurs in raw waters at a concerned level, appropriate treatment processes have to be applied to comply with the drinking water standards. At water treatment plants, UV radiation is regarded as a promising disinfection means due to its effectiveness in bacteria inactivation and leading to a low concentration of disinfection byproducts (Sharpless and Linden, 2001; Meunier et al., 2006). Moreover, direct photolysis was also reported to be responsible for the degradation of some organic compounds in advanced oxidation processes such as $\mathrm{UV} / \mathrm{O}_{3}$ and $\mathrm{UV} / \mathrm{H}_{2} \mathrm{O}_{2}$ (Adams and Randtke, 1992).

Even until now literatures about ETZ degradation, UV photodegradation included, are very limited. With this context in mind, this study was focused on the elimination of ETZ using UV radiation under conditions simulating those applied at water treatment plants. Furthermore, the reaction mechanism was proposed through identification of photodegradation byproducts. The detailed experimental scheme included: (1) study the photodegradation kinetics; (2) determine the quantum yield $(\Phi)$; (3) identify photodegradation byproducts; and (4) examine the feasibility of UV radiation for ETZ removal in natural waters.

\section{Materials and methods}

\subsection{Standards and reagents}

ETZ (99.5\% purity), N,O-bis(trimethylsilyl)-trifluoroacetamide (BSTFA) containing $1 \%$ trimethylchlorosilane and peroxidase from horseradish (lyophilized, 5KU) were purchased from 
Sigma-Aldrich. Atrazine (ATZ, 99\% purity) was obtained from the National Research Center for Certified Reference, China. Other chemicals used in this study were at least of analytical grade and used without further purification.

\subsection{Analytical methods}

ETZ and ATZ were determined with gas chromatograph/mass spectrometer (GC/MS) ( 7890 GC and 5975 MSD, Agilent) equipped with an HP-5 MS column $(30 \mathrm{~m} \times 0.25 \mathrm{~mm} \times 0.25 \mu \mathrm{m}$ film thickness). Helium gas was used as carrier gas at a flow rate of $1 \mathrm{~mL} \mathrm{~min}^{-1}$. The oven temperature started at $60^{\circ} \mathrm{C}$ and ramped linearly to $280^{\circ} \mathrm{C}$ at $30^{\circ} \mathrm{C} \mathrm{min}^{-1}$. The MS detector was operated in the electron ionization mode at $70 \mathrm{eV}$. The retention time for $\mathrm{ETZ}$ and ATZ was determined to be 7.5 and $8.6 \mathrm{~min}$, respectively. The quantification and confirmation ions used in the selected ion monitoring mode were 213, 211 and 183 for ETZ, and 215 and 200 for ATZ. The detection limits for ETZ and ATZ were 0.1 and $0.3 \mu \mathrm{M}$, respectively.

The concentration of $\mathrm{H}_{2} \mathrm{O}_{2}$ was determined by the peroxidaseDPD method (Bader et al., 1988). The concentrations of chloride, sulfate and nitrate were measured by a Metrohm 861 ion chromatograph. Total organic carbon (TOC) was analyzed with a TeKmar-Dohrmann Pheonix 8000 TOC analyzer.

\subsection{Experimental}

\subsubsection{Photodegradation kinetics in distilled water}

Photodegradation experiments were conducted in a 1-L cylindrical glass reactor filled with $1 \mathrm{~L}$ of fresh ETZ aqueous solution at $25 \pm 2{ }^{\circ} \mathrm{C}$. A low-pressure mercury vapor lamp primarily emitting radiation at $254 \mathrm{~nm}$ (nominal power $5 \mathrm{~W}$, produced by Beijing Electric Light Source Institute) was placed vertically in a quartz sleeve at the center of the reactor. Iodide/iodate actinometry, which was originally proposed by Rahn (1997) and further developed by Goldstein and Rabani (2008), was employed to determine the incident radiation flux of the UV lamp $\left(7.4 \times 10^{-7} \mathrm{E} \mathrm{s}^{-1}\right.$, equivalent to a power output of $350 \mathrm{~mW}$ ). The effective optical path length was thus calculated to be $4.0 \mathrm{~cm}$.

Several series of experiments were first carried out in distilled water by varying the initial ETZ concentration, $\mathrm{pH}$, and foreign substances. The initial ETZ concentration was varied in the range from 5 to $35 \mu \mathrm{M}$. The $\mathrm{pH}$ was adjusted with $10 \mathrm{mM}$ phosphate buffer (different ratios of $\mathrm{H}_{2} \mathrm{PO}_{4}^{-}$to $\mathrm{HPO}_{4}^{2-}$ ) to 6.0, 7.0 and 8.0, individually. Selected foreign substances, namely bicarbonate ( $1 \mathrm{mM})$, oxygen gas (flow rate $=1 \mathrm{~L} \mathrm{~min}^{-1}$ ) and nitrogen gas (flow rate $=1 \mathrm{~L} \mathrm{~min}^{-1}$ ) were introduced into the reaction system if required. At the onset of experiments, the lamp was allowed to warm up for $10 \mathrm{~min}$. Samples were withdrawn at preselected intervals, and each $5 \mathrm{~mL}$ of aqueous sample was extracted with $2 \mathrm{~mL}$ of methyl tert-butyl ether (MTBE) immediately after sampling. The extraction mixture was agitated for at least 2 min to ensure adequate contact between the water and MTBE layers. The MTBE layer was analyzed with GC/MS. $\mathrm{H}_{2} \mathrm{O}_{2}$, anions and TOC were also analyzed if required. All experiments were conducted in duplicate.

\subsubsection{Byproducts identification}

Solid-phase extraction (SPE) was applied to samples prior to the analysis and identification of photodegradation byproducts. Each reaction sample of $250 \mathrm{~mL}$ was extracted using a 500-mg Waters Oasis HLB extraction cartridge. The cartridge was conditioned in sequence with $5 \mathrm{~mL}$ of methanol and $5 \mathrm{~mL}$ of distilled water. After passage of the sample, the cartridge was vacuum-dried. The analytes were then eluted with $4 \mathrm{~mL}$ of dichloromethane and $4 \mathrm{~mL}$ of methanol successively into a glass tube. The eluate was evaporated to dryness under a gentle stream of nitrogen gas and then
$50 \mu \mathrm{L}$ of BSTFA and $50 \mu \mathrm{L}$ of pyridine were added. The glass tube was capped, vortexed for about $20 \mathrm{~s}$, and placed in $60^{\circ} \mathrm{C}$ water bath for $30 \mathrm{~min}$ to allow the derivatization reaction to complete. The mixture was allowed to cool down to room temperature and the residual BSTFA and pyridine were blown off under a gentle stream of nitrogen gas. Finally, the derivatives were dissolved in $250 \mu \mathrm{L}$ of hexane and analyzed by GC/MS. The GC oven temperature started at $40{ }^{\circ} \mathrm{C}$ and held for $2 \mathrm{~min}$, ramped at $3^{\circ} \mathrm{C} \mathrm{min}-1$ to $100{ }^{\circ} \mathrm{C}$ and held for $5 \mathrm{~min}$, ramped at $5^{\circ} \mathrm{C} \mathrm{min}^{-1}$ to $150{ }^{\circ} \mathrm{C}$, and further ramped at $20^{\circ} \mathrm{C} \mathrm{min}{ }^{-1}$ to $290^{\circ} \mathrm{C}$. The total analysis time for each sample was $46 \mathrm{~min}$.

\subsubsection{Photodegradation of etridiazole in natural waters}

Three natural waters in Beijing area were selected to examine the effect of water matrix on the photodegradation of ETZ under otherwise similar water treatment conditions: (1) groundwater collected from Changping District; (2) sand-filtered water prior to disinfection collected from the No. 9 Waterworks; and (3) surface water collected from Jingmi Trench. These waters were filtered through a $0.45-\mu \mathrm{m}$ cellulose filter and stored at $4{ }^{\circ} \mathrm{C}$ until use. The dissolved organic carbon (DOC) value was 1.2, 2.6 and $9.7 \mathrm{mg} \mathrm{L}^{-1}$ and the absorbance at $254 \mathrm{~nm}$ was $0.016,0.032$ and 0.048 for the groundwater, sand-filtered and surface water, respectively. ETZ was spiked at a low concentration of $1.4 \mu \mathrm{M}$, and the solution $\mathrm{pH}$ value was adjusted to 7.0. Samples were withdrawn at preselected time intervals, and the ETZ concentration was measured. The effective UV fluence rates of the reactor were calculated to be $2.95,2.87$ and $2.81 \mathrm{~mW} \mathrm{~cm}^{-2}$ for the groundwater, sand-filtered and surface water, respectively, based on the absorbance of the water samples and the reactor geometry using the point source summation method (White, 1999; Macauley et al., 2006).

\section{Results and discussion}

\subsection{Effects of initial etridiazole concentration and $\mathrm{pH}$}

Fig. 1A shows that increasing the initial ETZ concentration would decrease its degradation efficiency. First-order kinetics is generally used to express the photodegradation of a micropollutant, denoted as $C$ herein, in a vanishing absorption solution (Hessler et al., 1993),

$$
-\frac{\mathrm{d}[C]}{\mathrm{d} t}=2.3 \frac{\Phi \varepsilon I_{0} L[C]}{V}
$$

where $\varepsilon$ is the molar extinction coefficient; $I_{0}$ and $L$ denote the incident radiation flux and optical path length in the UV reactor, respectively; and $V$ represents the volume of reaction solution. As proposed by Nicole et al. (1990), in this case the optical density of the solution (i.e., $\varepsilon L C$ ) should be below 0.02 . The $\varepsilon$ value for ETZ was determined to be $720 \mathrm{M}^{-1} \mathrm{~cm}^{-1}$ in this work. Therefore, Eq. (1) was valid only when $C_{o}$ was less than $6.9 \mu \mathrm{M}$ considering an effective optical path length of $4.0 \mathrm{~cm}$. The corresponding firstorder rate constants $\left(k_{1}\right)$ for $C_{\mathrm{o}}=5 \mu \mathrm{M}$ were deduced, as shown in Table 1 . When $C_{\mathrm{o}}$ increased above $6.9 \mu \mathrm{M}$, the kinetics of photodegradation would deviate from the first-order rate law and start to approach the zero-order rate law (Hessler et al., 1993). Then, if the photodegradation of ETZ was approximated by the pseudofirst-order kinetics, the resulting rate constant would decrease as $C_{\mathrm{o}}$ increased from 5 to $30 \mu \mathrm{M}$.

Fig. 1B shows the change of normalized residual ETZ concentration with reaction time at different $\mathrm{pH}$ values ranging from 6.0 to 8.0, which represents the typical condition in drinking water treatment plants. The similar first-order rate constants in Table 1 indicate the negligible $\mathrm{pH}$ dependence of ETZ photodegradation. In the neutral $\mathrm{pH}$ range, deprotonated ETZ is the primary form in water 


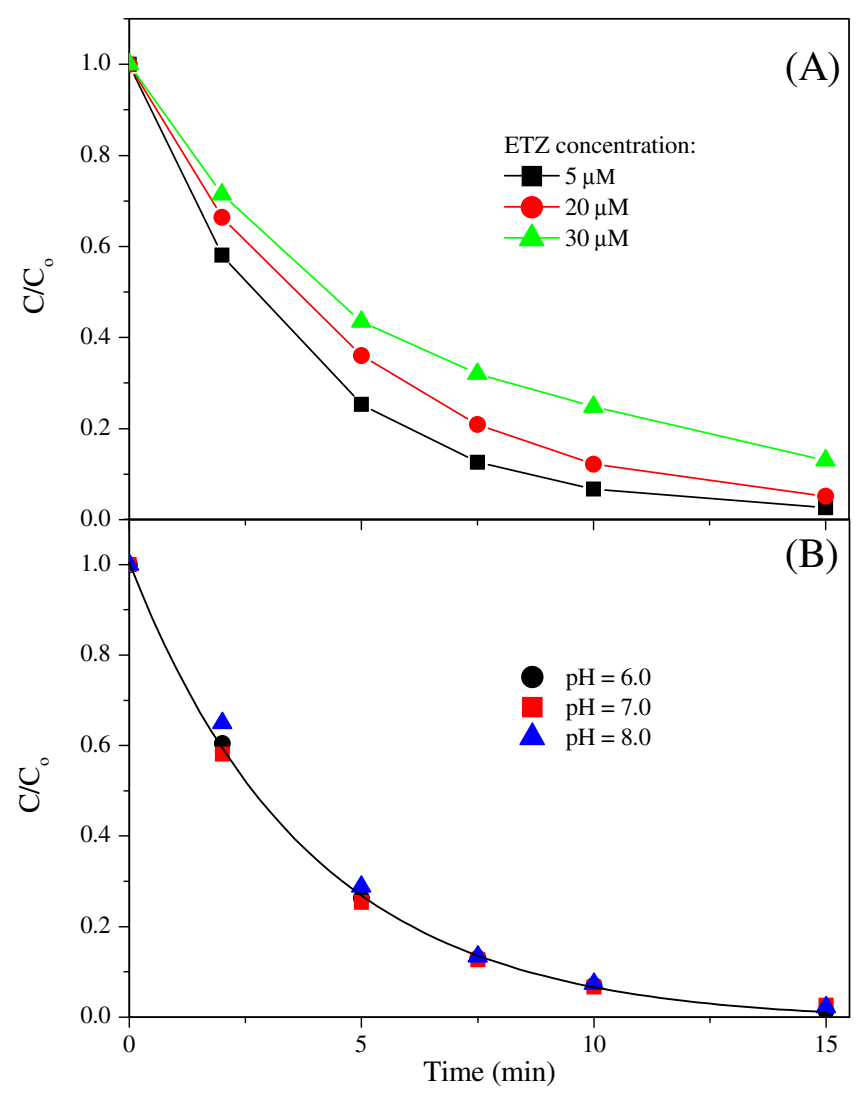

Fig. 1. Photodegradation of ETZ: (A) effect of initial ETZ concentration, $\mathrm{pH}=7.0$ and (B) effect of $\mathrm{pH},[\mathrm{ETZ}]_{\mathrm{o}}=5 \mu \mathrm{M}$. The standard deviation of all data points was below $5 \%$.

Table 1

First-order and pseudo-first-order rate constants of ETZ photodegradation under different experimental conditions in distilled water. Experimental conditions: incident radiation flux of UV lamp $=7.4 \times 10^{-7} \mathrm{E} \mathrm{s}^{-1}, T=25 \pm 2{ }^{\circ} \mathrm{C}$, [bicarbonate $]=1 \mathrm{mM}$, nitrogen gas flow rate $=1 \mathrm{~L} \mathrm{~min}^{-1}$, oxygen gas flow rate $=1 \mathrm{~L} \mathrm{~min}^{-1}$.

\begin{tabular}{lclllll}
\hline Run & $C_{\mathrm{o}}(\mu \mathrm{M})^{\mathrm{a}}$ & $\mathrm{pH}$ & Foreign substance & $k_{1} \times 10^{3}\left(\mathrm{~s}^{-1}\right)^{\mathrm{b}}$ & $R^{2}$ & $t_{1 / 2}(\mathrm{~min})$ \\
\hline 1 & 5 & 7.0 & None & 4.3 & 0.990 & 2.7 \\
2 & 20 & 7.0 & None & $3.4^{\mathrm{c}}$ & 0.998 & 3.4 \\
3 & 30 & 7.0 & None & $2.6^{\mathrm{c}}$ & 0.997 & 4.5 \\
4 & 5 & 6.0 & None & 4.5 & 0.999 & 2.6 \\
5 & 5 & 8.0 & None & 4.3 & 0.998 & 2.7 \\
6 & 5 & 7.0 & Bicarbonate & 4.3 & 0.983 & 2.7 \\
7 & 5 & 7.0 & Nitrogen & 4.1 & 0.995 & 2.8 \\
8 & 5 & 7.0 & Oxygen & 4.0 & 0.998 & 2.9 \\
\hline
\end{tabular}

a Initial ETZ concentration.

b First-order rate constant.

c Pseudo-first-order rate constant.

( $\mathrm{p} K_{\mathrm{a}}=2.77$, Tomlin, 2003). The insignificant $\mathrm{pH}$ influence on UV photodegradation rate of neutral propachlor was also reported by Benitez et al. (2004). Thus, no pH adjustment is required for eliminating ETZ by UV radiation in drinking water treatment.

\subsection{Determination of quantum yield}

A competition kinetic model has been previously used to determine the $\Phi$ value of a given organic compound (Benitez et al., $2004)$. According to this method, the $\Phi$ value of ETZ can be determined from the simultaneous photodegradation of a mixture of ETZ and ATZ. ATZ, whose $\Phi$ is known, was used as a reference compound in this study. Therefore, the following equation applies:

$$
\frac{\mathrm{d} C_{\mathrm{E}}}{\mathrm{d} C_{\mathrm{A}}}=\frac{\Phi_{\mathrm{E}} \varepsilon_{\mathrm{E}} C_{\mathrm{E}}}{\Phi_{\mathrm{A}} \varepsilon_{\mathrm{A}} C_{\mathrm{A}}}
$$

where E and A are referred to ETZ and ATZ, respectively. By rearrangement and upon integration of Eq. (2) we have:

$\ln \frac{C_{\mathrm{Eo}}}{C_{\mathrm{E}}}=\alpha \ln \frac{C_{\mathrm{Ao}}}{C_{\mathrm{A}}}$

where $C_{\mathrm{Eo}}$ and $C_{\mathrm{Ao}}$ are the initial ETZ and ATZ concentrations, and

$\alpha=\frac{\Phi_{\mathrm{E}} \varepsilon_{\mathrm{E}}}{\Phi_{\mathrm{A}} \varepsilon_{\mathrm{A}}}$

The plot of $\ln \left(C_{\mathrm{Eo}} / C_{\mathrm{E}}\right)$ vs. $\ln \left(C_{\mathrm{Ao}} / C_{\mathrm{A}}\right)$ was shown in Fig. 2 . The $\alpha$ value obtained was 2.76. The $\Phi$ and $\varepsilon$ values of ATZ are $0.033 \mathrm{~mol} \mathrm{E}^{-1}$ and $3683 \mathrm{M}^{-1} \mathrm{~cm}^{-1}$, respectively (Bolton and Stefan, 2002). Thus, the $\Phi$ value for ETZ was calculated to be $0.46 \pm 0.02 \mathrm{~mol} \mathrm{E}^{-1}$ at $\mathrm{pH} 7.0$. This high $\Phi$ indicates that ETZ undergoes a fast photodegradation process.

\subsection{Effect of foreign substances}

The decomposition of an organic compound in photochemical processes may proceed via two pathways: (1) direct photodegradation in which the organic compound absorbs photons to get decomposed; (2) indirect photodegradation in which reactive intermediates generated from UV photolysis of the target compound and/or other co-existing substrates further react with the target compound (Lam and Mabury, 2005). The most common reactive intermediates formed in aquatic photochemical processes are reactive oxygen species (ROS) such as $\mathrm{H}_{2} \mathrm{O}_{2}$, hydroxyl radical and superoxide radical. $\mathrm{H}_{2} \mathrm{O}_{2}$ can be generated in photochemical processes (Qiang et al., 2002), and its concentration up to $50 \mu \mathrm{M}$ was detected during the UV degradation of ATZ (Beltrán et al., 1993). To investigate the influence of the ROS formed on the ETZ photodegradation, several foreign substances (i.e., bicarbonate, dissolved oxygen and nitrogen) were introduced to the reaction system.

Fig. $3 \mathrm{~A}$ shows that although $\mathrm{H}_{2} \mathrm{O}_{2}$ was generated at somewhat varied rates in the presence of different foreign substances, all its concentrations were at trace levels (i.e., from 0 to $1.0 \mu \mathrm{M}$ ). It was also reported by Beltrán et al. (1993) that the presence of bicarbonate had no notable effect on $\mathrm{H}_{2} \mathrm{O}_{2}$ formation during ATZ photodegradation.

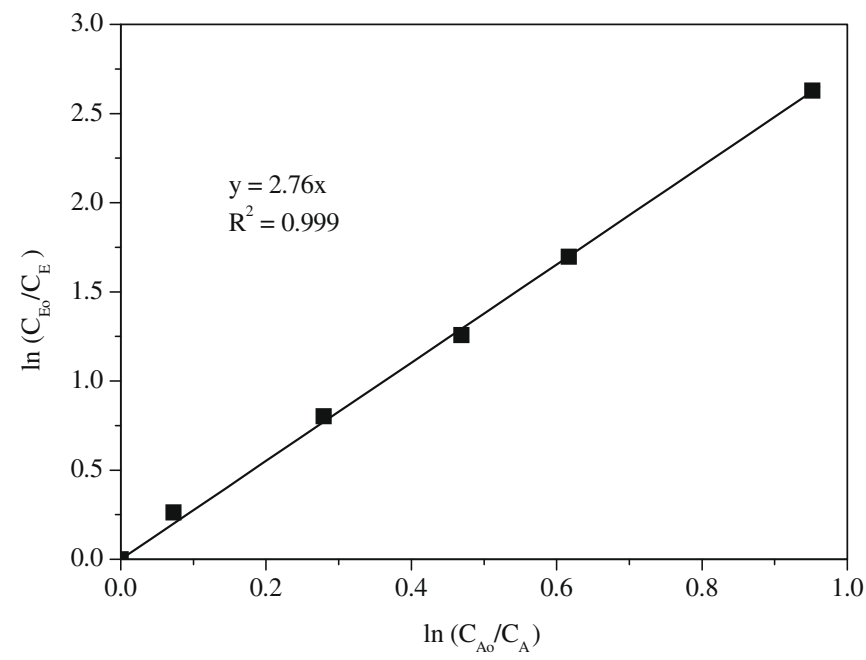

Fig. 2. Plot of $\ln \left(C_{\mathrm{EO}} / C_{\mathrm{E}}\right)$ vs. $\ln \left(C_{\mathrm{Ao}} / C_{\mathrm{A}}\right)$. Experimental conditions: $\mathrm{pH}=7.0$, $[\mathrm{ETZ}]_{\mathrm{o}}=5 \mu \mathrm{M},[\mathrm{ATZ}]_{\mathrm{o}}=5 \mu \mathrm{M}$. The subscripts $\mathrm{E}$ and A represent ETZ and ATZ, respectively. The standard deviation of duplicate analyses was below $5 \%$. 
The generated $\mathrm{H}_{2} \mathrm{O}_{2}$ can undergo rapid photolysis under UV radiation (Nicole et al., 1990), yielding a photolysis product, namely hydroxyl radical. Since bicarbonate is a well-known hydroxyl radical scavenger, experiments were conducted to study the effect of bicarbonate on the degradation of ETZ. Fig. 3B shows that the ETZ degradation was not affected by the addition of bicarbonate, indicating a negligible hydroxyl radical contribution to ETZ degradation. Although bicarbonate is ubiquitous in natural waters, the results indicate that UV radiation is applicable to ETZ removal in natural waters when bicarbonate is present.

Lee et al. (2005) reported that due to the formation of superoxide radicals, a notable increase in photodegradation rate of N-nitrosodimethylamine was found in $\mathrm{O}_{2}$ saturated solution, compared to that in $\mathrm{N}_{2}$ saturated solution. However, Fig. 3B clearly shows that the ETZ photodegradation rates were very similar in the two reaction solutions respectively saturated with $\mathrm{O}_{2}$ and $\mathrm{N}_{2}$, implying the negligible ROS involvement. Therefore, it is concluded that the decomposition of ETZ by UV radiation occurred predominantly via direct photodegradation in distilled water in our reaction system.

\subsection{Proposed photodegradation mechanism}

Fig. 4 shows the identification of organic byproducts, mass balance on chlorine atom and removal of TOC. By analyzing the ex-
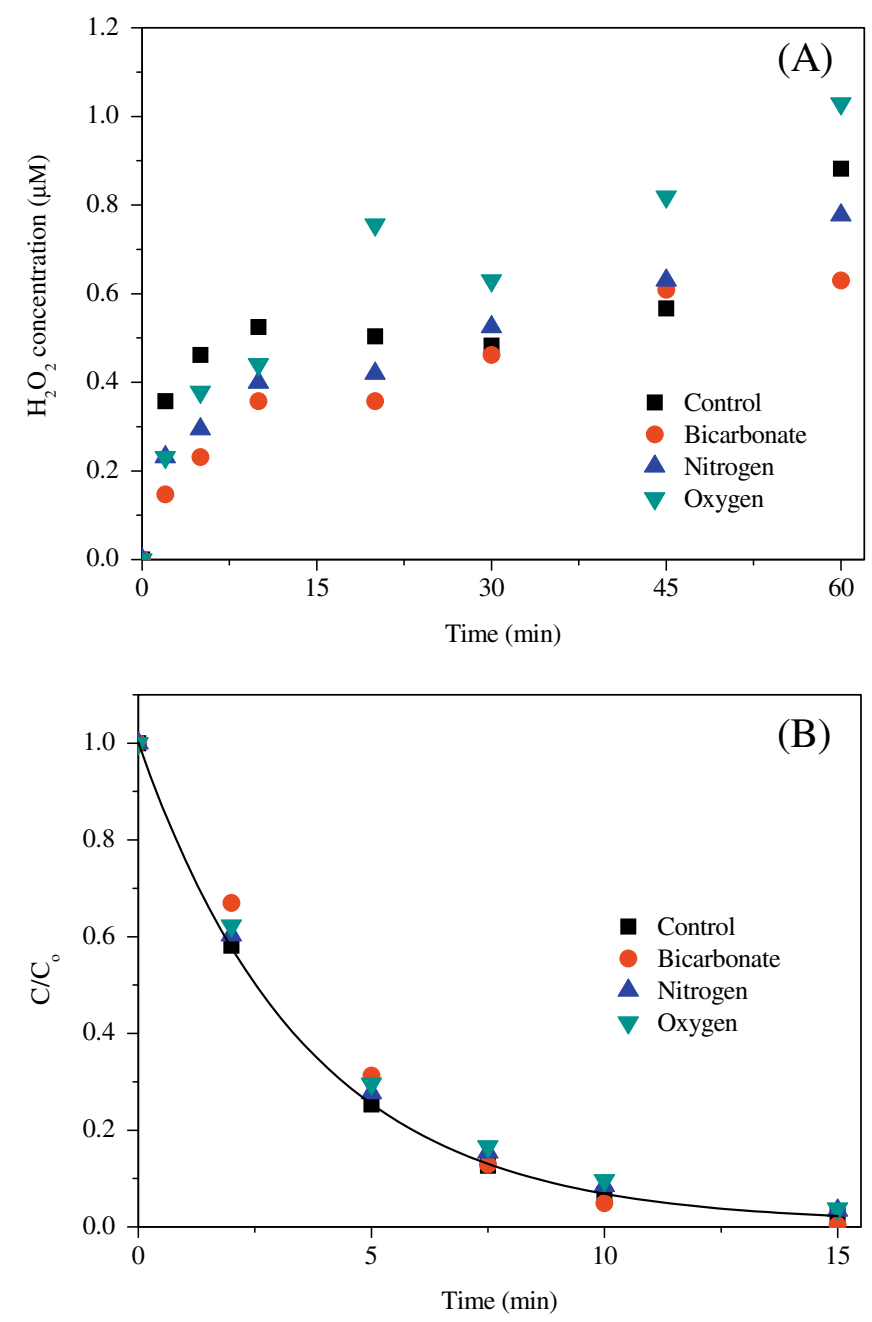

Fig. 3. Effects of foreign substances on: (A) $\mathrm{H}_{2} \mathrm{O}_{2}$ formation, [ETZ $]_{\mathrm{o}}=35 \mu \mathrm{M}$ and (B) ETZ degradation, $[\mathrm{ETZ}]_{\mathrm{o}}=5 \mu \mathrm{M}$. Experimental conditions: $\mathrm{pH}=7.0$, [bicarbonate $]=1 \mathrm{mM}$, nitrogen gas flow rate $=1 \mathrm{~L} \mathrm{~min}^{-1}$, oxygen gas flow rate $=1 \mathrm{~L} \mathrm{~min}^{-1}$. The standard deviation of all data points was below $5 \%$. tract from reaction solution with GC/MS, several pertinent peaks were tentatively identified as presented in Fig. 4A.

Comparing with the standard mass spectrum of ETZ, the probability of compound 1 being ETZ was 99\%. ETZ has a molecular ion at $\mathrm{m} / \mathrm{z} 246$, an isotopic molecular ion containing one ${ }^{37} \mathrm{Cl}$ atom at $\mathrm{m} / \mathrm{z}$ 248 , and an abundant ion at $m / z 211$ resulting from the loss of one ${ }^{35} \mathrm{Cl}$ atom in the trichloromethyl group.

Compound 2 with a molecular ion at $m / z 212$ could correspond to 5-ethoxy-3-dichloromethyl-1,2,4-thiadiazole. It has an isotopic molecular ion containing one ${ }^{37} \mathrm{Cl}$ atom at $\mathrm{m} / z 214$ and an abundant ion at $m / z 184$ with the loss of $\mathrm{C}_{2} \mathrm{H}_{4}$ in the ethoxyl group. The fragments agreed well with the mass spectrum previously reported by Van Welie et al. (1991).

Compound 3 with a molecular ion at $m / z 246$ may correspond to the silanized derivative of 5-ethoxy-1,2,4-thiadiazole-3-carboxylic acid. The molecular ion could lose $\mathrm{CH}_{3}$ to give the ion at $\mathrm{m} / \mathrm{z} 231$ which would lose $\mathrm{C}_{2} \mathrm{H}_{4}$ in the ethoxyl group to give the ion at $\mathrm{m} /$ $z$ 203. The molecular ion at $m / z 246$ could also lose the silane group to yield an ion at $m / z$ 173. 5-Ethoxy-1,2,4-thiadiazole-3-carboxylic acid was identified as a biotransformation metabolite in the urine of rat and man (Van Welie et al., 1991).

Compound 4 with a molecular ion at $m / z 218(\mathrm{M})$ may correspond to the silanized derivative of 5-ethoxy-3-hydroxyl-1,2,4thiadiazole. It has two isotopic molecular ions at $\mathrm{m} / \mathrm{z} 219(\mathrm{M}+1)$ and at $m / z 220(M+2)$. The normalized intensities of $M, M+1$ and $M+2$ were $100,13.4$ and 7.7 , which were very similar to the values of $100,14.6$, and 9.1 , respectively, based on the isotopic calculation. The molecular ion could lose $\mathrm{CH}_{3}$ to give an ion at $m / z 203$. Further loss of $\mathrm{C}_{2} \mathrm{H}_{4}$ in the ethoxyl group could produce an ion at $\mathrm{m} / \mathrm{z} 175$. It is noted that 5-ethoxy-3-hydroxyl-1,2,4-thiadiazole has never been reported before.

Fig. 4B shows chloride ion release and TOC removal as a function of reaction time. It should be mentioned that no notable formation of nitrate and sulfate ions were observed even when ETZ was completely degraded. Nitrogen and sulfur atoms remained in the thiadiazole ring. Chloride ion was the major anionic byproduct which accounted for about $90 \%$ with respect to chlorine mass at 60 min. Most chloro initially present in ETZ was released as chloride ion to the solution eventually, indicating that compound $\mathbf{2}$ was a minor species. The low removal efficiency of TOC indicates that ETZ could not be mineralized by UV radiation.

Fig. 5 illustrates the proposed mechanism for ETZ photodegradation. In this study, dechlorination of the trichloromethyl moiety and substitution of the trichloromethyl group by $\mathrm{OH}$ group occurred during photodegradation of ETZ in water by UV radiation. The homolysis of $\mathrm{C}-\mathrm{Cl}$ bond was found to be the major step of photodegradation of captan and butachlor (Schwack and Flößer-Müller, 1990; Zheng and Ye, 2001). The homolytic cleavage of $\mathrm{C}-\mathrm{Cl}$ bond would lead to the replacement of chloro by $\mathrm{OH}$ group and $\mathrm{H}$ atom (Burrows et al., 2002). Compound 2 could form via the latter pathway if sufficient hydrogen donors were present (Schwack and Flößer-Müller, 1990). In aqueous solution, however, this substitution is generally not favored. Therefore, the degree of formation of compound 2 was insignificant, which agrees well with results shown in Fig. 4B. Once the replacement of chloro by $\mathrm{OH}$ group advanced completely, 5-ethoxy-1,2,4-thiadiazole-3-carboxylic acid (compound $\mathbf{5}$ ) would be generated. Its formation was also favored by the decrease of $\mathrm{pH}$ during the photodegradation of ETZ when phosphate buffer was absent. The cleavage of $\mathrm{C}-\mathrm{C}$ bond which connects the trichloromethyl moiety with the thiadiazole ring could probably occur under UV radiation. Then, the replacement of the trichloromethyl moiety with $\mathrm{OH}$ group would yield 5-ethoxy-3-hydroxyl-1,2,4-thiadiazole (compound 6).

Besides the identification of organic byproducts, their toxicity should also be concerned because the organic byproducts can sometimes be more toxic than the parent compound (Verstraeten 

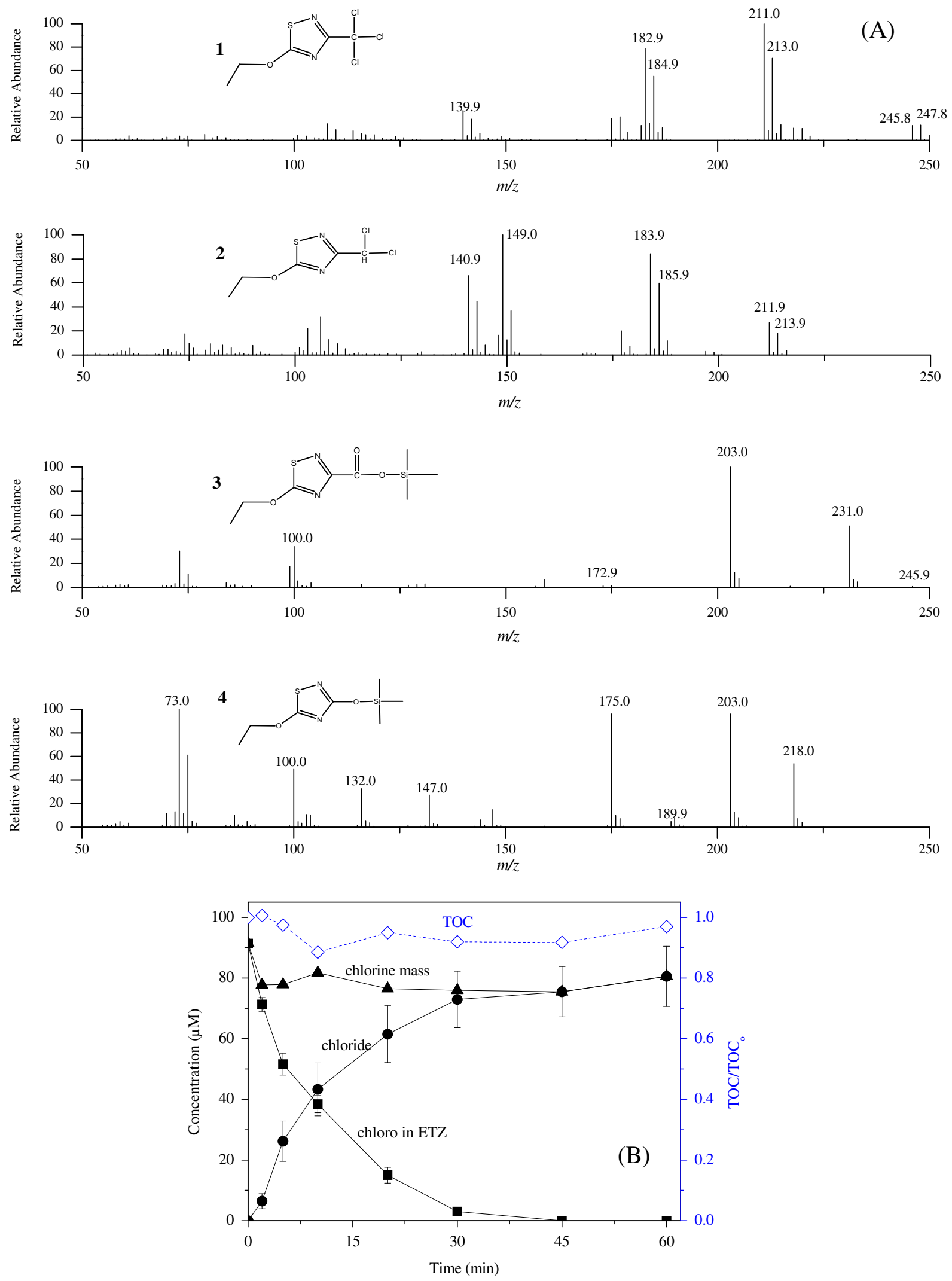

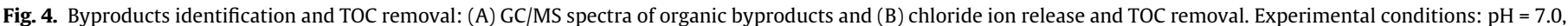
$[\mathrm{ETZ}]_{\mathrm{o}}=30 \mu \mathrm{M}$. The Arabic numbers are assigned to identify the compounds. Error bars represent the standard deviation of duplicate analyses.

et al., 2002). Compound 2 was found to be highly toxic on an acute basis (US EPA, 2000). The toxicity of compounds 5 and $\mathbf{6}$ was unknown, but their fungitoxicity can be expected to be lower due to the lack of trichloromethyl moiety which leads to the fungitoxicity of captan (Lukens, 1966). From safe-guarding the drinking water quality point of view, additional research about the chronic 
<smiles>CCOc1nc(C(Cl)(Cl)Cl)ns1</smiles>

(1)<smiles>CCOc1nc(C(Cl)(Cl)Cl)ns1</smiles><smiles>CCOc1n[c]ns1</smiles>
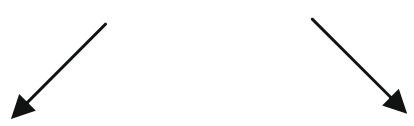<smiles>CCOc1nc(C(Cl)Cl)ns1</smiles>

(2)<smiles>CCOc1nc(C(O)(Cl)Cl)ns1</smiles><smiles>CCOc1nc(O)ns1</smiles>

(6)
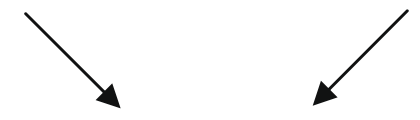<smiles>CCOc1nc(C(=O)O)ns1</smiles>

Fig. 5. Proposed mechanism for photodegradation of ETZ. The Arabic numbers are assigned to identify the compounds.

dietary risk of ETZ degradation byproducts to human health should be addressed in the future.

\subsection{Photodegradation of etridiazole in natural waters}

To assess the effectiveness of ETZ removal by UV radiation in water treatment plants, additional experiments were carried out in natural waters including groundwater, sand-filtered water and surface water. Fig. 6 shows the change of normalized residual ETZ concentration as a function of UV fluence (UV dose, the product of UV fluence rate and irradiation time) in the three water media. The removal efficiency of ETZ was about 10 and $90 \%$ at the UV dose of 40 and $1375 \mathrm{~mJ} \mathrm{~cm}^{-2}$, respectively. The UV dose of $40 \mathrm{~mJ} \mathrm{~cm}^{-2}$ is typically applied at water treatment plants (Meunier et al., 2006). As indicated above, the photodegradation of ETZ with a low concentration can be expressed by the first-order kinetics. As a result, the photodegradation rate constant of ETZ is independent of its initial concentration. By analogy, even if ETZ is present in water resource at a concentration of less than $1.4 \mu \mathrm{M}$, an ineffective removal can be reasonably deduced at the typical UV dose of $40 \mathrm{~mJ} \mathrm{~cm}^{-2}$.
Results also indicate that among the three water media, the comparatively fastest ETZ removal was observed in the groundwater, followed by those in the sand-filtered water and surface water. Natural organic matter (NOM) is ubiquitously present in natural waters. NOM can impede the photodegradation of target compound through competitive absorption of UV radiation (Benitez et al., 2004). The groundwater had the lowest DOC concentration (i.e., $1.2 \mathrm{mg} \mathrm{L}^{-1}$ ), which tends to account for the fastest photodegradation of ETZ. The indirect photodegradation was insignificant in natural waters in this study; otherwise the fastest photodegradation of ETZ would have occurred in the surface water which had the highest TOC concentration of $9.7 \mathrm{mg} \mathrm{L}^{-1}$.

UV in combination with $\mathrm{O}_{3}$ or $\mathrm{H}_{2} \mathrm{O}_{2}$ could enhance the destruction of micropollutants compared to UV alone (Hessler et al., 1993; Benitez et al., 2004). In order to meet the drinking water regulations for pesticides, ETZ included, $\mathrm{UV} / \mathrm{O}_{3}$ or $\mathrm{UV} /$ $\mathrm{H}_{2} \mathrm{O}_{2}$ which produces abundant hydroxyl radicals is expected to be more effective in pesticide degradation. Hydroxyl radicals can react very quickly towards pesticides with second-order rate constants generally ranging from $10^{8}$ to $10^{10} \mathrm{M}^{-1} \mathrm{~s}^{-1}$ (Buxton et al., 1988). 


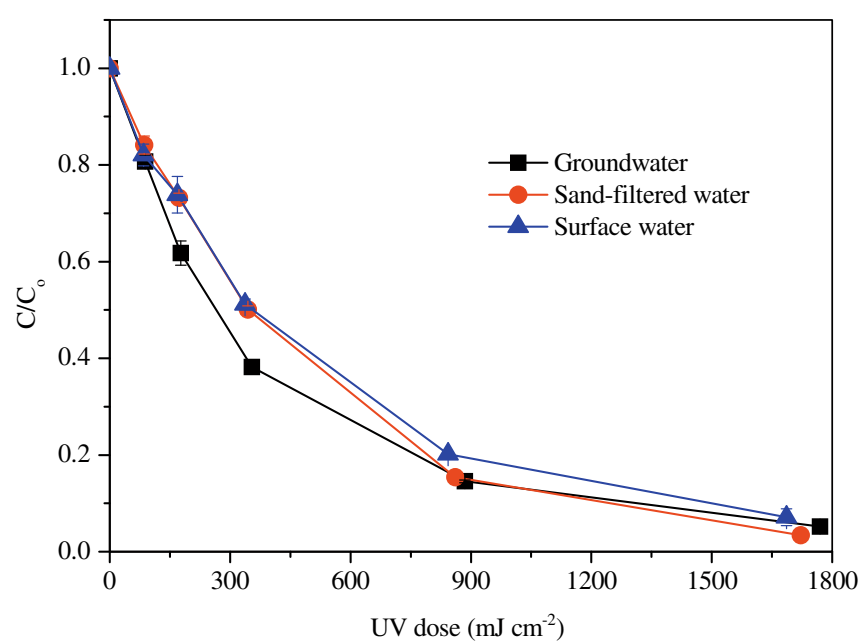

Fig. 6. Photodegradation of ETZ in natural waters. Experimental conditions: $\mathrm{pH}=7.0,[\mathrm{ETZ}]_{\mathrm{o}}=1.4 \mu \mathrm{M}$. Error bars represent the standard deviation of duplicate analyses.

\section{Conclusions}

The simulated first-order rate constants decreased with the increase of initial ETZ concentration (i.e., 5, 20 and $30 \mu \mathrm{M}$ ), and was independent of the solution $\mathrm{pH}$ within the range of 6.0 to 8.0. The $\Phi$ value of ETZ was determined to be $0.46 \pm 0.02 \mathrm{~mol} \mathrm{E}^{-1} \cdot \mathrm{H}_{2} \mathrm{O}_{2}$ was generated at trace levels and had little influence on photodegradation of ETZ. Direct photodegradation was the major mechanism for the decomposition of ETZ in distilled water by UV radiation.

Three organic byproducts, namely, 5-ethoxy-3-dichloromethyl1,2,4-thiadiazole, 5-ethoxy-1,2,4-thiadiazole-3-carboxylic acid, and 5-ethoxy-3-hydroxyl-1,2,4-thiadiazole, were identified. The degree of dechlorination of ETZ reached about $90 \%$ at the end of reaction, while nitrate and sulfate were not detectable. The degree of mineralization was insignificant as indicated by the removal efficiency of TOC.

The fastest ETZ degradation was observed in groundwater, compared to sand-filtered water and surface water, probably due to the competitive absorption of UV radiation by NOM. Based on the results obtained, it could be expected that ETZ would not be removed effectively at the UV dose of $40 \mathrm{~mJ} \mathrm{~cm} \mathrm{~cm}^{-2}$ which was typically applied for drinking water disinfection.

\section{Acknowledgements}

We are grateful to Professor C.P. Huang at the Department of $\mathrm{Ci}$ vil and Environmental Engineering, University of Delaware, USA, for his comments and suggestions on this manuscript. The work was funded by National Natural Science Foundation of China (20677071) and Key Technology R\&D Program, Ministry of Science and Technology of China (2006BAJ08B02, 2006BAJ08B10).

\section{References}

Adams, C.D., Randtke, S.J., 1992. Ozonation byproducts of atrazine in synthetic and natural waters. Environ. Sci. Technol. 26, 2218-2227.
Bader, H., Sturzenegger, V., Hoingné, J., 1988. Photometric method for the determination of low concentrations of hydrogen peroxide by the peroxidase catalyzed oxidation of N, N-diethyl-p-phenylenediamine. Water Res. 22, 11091115.

Beltrán, FJ. Ovejero, G., Acedo, B., 1993. Oxidation of atrazine in water by ultraviolet radiation combined with hydrogen peroxide. Water Res. 27, 10131021.

Benitez, F.J., Acero, J.L., Real, F.J., Maya, C., 2004. Modeling of photooxidation of acetamide herbicides in natural waters by UV radiation and the combinations $\mathrm{UV} / \mathrm{H}_{2} \mathrm{O}_{2}$ and $\mathrm{UV} / \mathrm{O}_{3}$. J. Chem. Technol. Biot. 79, 987-997.

Bolton, J., Stefan, M., 2002. Fundamental photochemical approach to the concepts of fluence (UV dose) and electrical energy efficiency in photochemical degradation reactions. Res. Chem. Intermediat. 28, 857-870.

Burrows, H.D., Canle, M., Santaballa, J.A., Steenken, S., 2002. Reaction pathways and mechanisms of photodegradation of pesticides. J. Photochem. Photobiol. B 67, 71-108.

Buxton, G., Greenstock, C., Helman, W., Ross, A., 1988. Critical review of rate constants for reactions of hydrated electrons, hydrogen atoms and hydroxyl radicals $\left({ }^{\circ} \mathrm{OH} / \mathrm{O}^{-}\right)$in aqueous solution. J. Phys. Chem. Ref. Data 17, 513-886.

Dalvi, R.R., Howell, C.D., 1977. Toxic effects of a fungicide, 5-ethoxy-3(trichloromethyl)-1,2,4 thiadiazole (terrazole), on the hepatic drug metabolizying enzyme system in mice. Bull. Environ. Contam. Toxicol. 17, 225-235.

European Union, 2007. European Communities (Drinking Water) No. 2 Regulations 2007. S.I. No. 278. Brussels, pp. 22-23.

Goldstein, S., Rabani, J., 2008. The ferrioxalate and iodide-iodate actinometers in the UV region. J. Photochem. Photobiol. A 193, 50-55.

Hessler, D.P., Gorenflo, V., Frimmel, F.H., 1993. Degradation of aqueous atrazine and metazachlor by $\mathrm{UV}$ and $\mathrm{UV} / \mathrm{H}_{2} \mathrm{O}_{2}$ - influence of $\mathrm{pH}$ and herbicide concentration. Acta Hydrochem. Hydrobiol. 21, 209-214.

Lam, M.W., Mabury, S.A., 2005. Photodegradation of the pharmaceuticals atorvastatin, carbamazepine, levofloxacin, and sulfamethoxazole in natural waters. Aquat. Sci. 67, 177-188.

Lee, C., Choi, W., Yoon, J., 2005. UV photolytic mechanism of Nnitrosodimethylamine in water: roles of dissolved oxygen and solution $\mathrm{pH}$. Environ. Sci. Technol. 39, 9702-9709.

Lukens, R.J., 1966. Fungitoxicity of compounds containing a trichloromethylthiogroup. J. Agr. Food Chem. 14, 365-367.

Macauley, J.J., Qiang, Z., Adams, C.D., Suramplli, R., Mormile, M.R., 2006. Disinfection of swine wastewater using chlorine, ultraviolet light and ozone. Water Res. 40, 2017-2026.

Meunier, L., Canonica, S., von Gunten, U., 2006. Implications for sequential use of UV and ozone for drinking water quality. Water Res. 40, 1864-1876.

National Health and Medical Research Council of Australia, 2004. Australian Drinking Water Guidelines. Carberra

Nicole, I., De Latt, J., Dore, M., Bonnel, C., 1990. Use of U.V. radiation in water treatment: measurement of photonic flux by hydrogen peroxide actinometry. Water Res. 24, 157-168.

Office of Prevention, Pesticides and Toxic Substances, 2000. Reregistration Eligibility Decision for Etridiazole. US Environmental Protection Agency, Washington, DC

Peck, A.M., Hornbuckle, K.C., 2005. Gas-phase concentrations of current-use pesticides in Iowa. Environ. Sci. Technol. 39, 2952-2959.

Qiang, Z., Chang, J.H., Huang, C.P., 2002. Electrochemical generation of hydrogen peroxide from dissolved oxygen in acidic solutions. Water Res. 36, 85-94.

Rahn, R.O., 1997. Potassium iodide as a chemical actinometer for $254 \mathrm{~nm}$ radiation: use of iodate as an electron scavenger. Photochem. Photobiol. 66, 450-455.

Schwack, W., Flößer-Müller, H., 1990. Fungicides and photochemistry. Photodehalogenation of captan. Chemosphere 21, 905-912.

Sharpless, C.M., Linden, K.G., 2001. UV photolysis of nitrate: effects of natural organic matter and dissolved inorganic compound and implications for UV water disinfection. Environ. Sci. Technol. 35, 2949-2955.

Tomlin, C., 2003. The Pesticide Manual, A World Compendium, 13th ed. British Crop Protection Council, Farnham, Surrey, UK.

Van Welie, R.T.H., Mensert, R., Van Duyn, P., Vermeulen, N.P.E., 1991. Identification and quantitative determination of a carboxylic and a mercapturic acid metabolite of etridiazole in urine of rate and man. Potential tools for biological monitoring. Arch. Toxicol. 65, 625-632.

Verstraeten, I.M., Thurman, E.M., Lindsey, M.E., Lee, E.C., Smith, R.D., 2002. Changes in concentrations of triazine and acetamide herbicides by bank filtration, ozonation, and chlorination in a public water supply. J. Hydrol. 266, 190-208.

White, G.C., 1999. The Handbook of Chlorination and Alternative Disinfectants, fourth ed. John Wiley \& Sons, Inc., New York. pp. 1440-1442.

Zheng, H., Ye, C., 2001. Identification of UV photoproducts and hydrolysis products of butachlor by mass spectrometry. Environ. Sci. Technol. 35, 2889-2895. 